\title{
CÁDIZ EN EL SISTEMA ATLÁNTICO. LA CIUDAD, SUS COMERCIANTES Y LA ACTIVIDAD MERCANTIL, (1650-1830)
}

\author{
Manuel Bustos Rodríguez \\ Editado por UCA y Silex, Madrid, 2005.
}

Con el título Cádiz en el sistema Atlántico, Manuel Bustos nos pone en contacto con la actual historia socioeconómica, que tiende a buscar nuevos espacios de relación y contacto entre los pueblos, fuera de las tradicionales fronteras de las naciones o de los bloques territoriales de los continentes. Así la ciudad de Cádiz se nos presenta en este estudio como una pieza constitutiva del sistema atlántico, nombre que sirve para designar el complejo entramado comercial y social tejido entre ambas orillas del océano. En este contexto Manuel Bustos analiza la ciudad, sus comerciantes y la actividad mercantil entre los años 1650 y 1830. Este amplio marco cronológico le permite, no solo incluir todas las aportaciones existentes hasta el momento sobre la historia de Cádiz, sino añadir un periodo poco querido por los historiadores modernistas, concretamente los años posteriores al libre comercio y los comienzos del siglo XIX hasta el momento en que se consolida la secesión americana. Este amplio espacio temporal añade un valor especial a este estudio al permitir a su autor observar los cambios desde la perspectiva del tiempo largo.

El libro está estructurado en seis estudios o capítulos bien delimitados, que comienzan por un análisis pormenorizado de Cádiz, como modelo de ciudad mercantil y portuaria, con unas especificidades propias que le otorgan su propia situación geográfica y su situación privilegiada en el Monopolio.

En los capítulos sucesivos encontramos un examen sistemático del grupo mercantil; prestando especial atención a los extranjeros, y dentro de estos, a la colonia francesa, que estudia con exhaustividad, utilizando, sobre todo, la documentación generada por el propio consulado francés en Cádiz.

A continuación dedica un nuevo capítulo a la trayectoria profesional de estos comerciantes, su formación y su capacidad de socialización dentro de su propio grupo, y en el interior de la sociedad gaditana. La visión sobre los comerciantes gaditanos queda completada con el siguiente capítulo dedicado a informarnos sobre la mentalidad y el talante utilitarista de los hombres de negocio.

Las actividades y los tipos de negocio en los que invirtieron estos comerciantes, así como la forma como obtenían los beneficios y como se arruinaban, son el objeto del capitulo siguiente. Manuel Bustos se detiene aquí en explicarnos las distintas estrategias 
inversoras de los hombres de negocio gaditanos y su evolución durante el periodo considerado. Analiza la preferencia por los riesgos marítimos, el interés creciente de los comerciantes por el comercio especulativo de letras de cambio, particularmente en los años finales del siglo XVIII, y los negocios emergentes de las compañías de seguros también en esos años.

A lo largo de todos estos capítulos, ha ido construyendo Cádiz como un modelo de ciudad inserta en un sistema que durante más de tres siglos se fundamentó en una densa red de relaciones, que fueron al mismo tiempo económicas, políticas y culturales. Pero ese modelo en sus últimos cincuenta años comenzaría una larga agonía que para Manuel Bustos terminará en 1830 .

El capítulo final, pues, está dedicado a analizar las dificultades que surgieron a finales del siglo XVIII y la incapacidad del modelo para encararlas de manera realista y productiva. El proyecto de 1778 que se presentaba como una actualización del modelo y la solución a los problemas que se habían ido presentando a lo largo del siglo, fue percibido por los comerciantes gaditanos como el principio del fin de sus negocios y de su forma de comerciar. Incluso con la perspectiva que dan los años, en 1815 el Cabildo gaditano se quejará del desacierto que supuso aquella reforma.

Los sucesivos bloqueos, las guerras y las epidemias colocarían a la ciudad durante estos años de entre siglos en una situación dramática, y tal y como concluye Manuel Bustos la situación creada apaga prácticamente las iniciativas que habían ido naciendo a lo largo, fundamentalmente del siglo XVIII en concreto las empresas manufactureras y el negocio asegurador.

La falta de expectativas de estos años llevarán al comercio gaditano a recurrir a viejos métodos para parchear su delicada situación. Así, se potencian negocios como el contrabando y el corso, y otros de carácter especulativo como el comercio de letras de cambio, o se entablan contactos comerciales con países alejados de los conflictos, como Rusia.

Finalmente el modelo construido a lo largo del siglo XVIII se hunde, sin que Cádiz. acierte a establecer una alternativa de carácter global compensatoria.

Disponemos, por tanto en nuestras bibliotecas de un libro valioso para los que nos interesamos por la historia marítima. Un libro que recupera la unidad del periodo que ya señalaran Antonio García Baquero y Antonio Miguel Bernal y que no termina con los bloqueos y guerras de finales del siglo XVIII, sino cuando el modelo colonial periclita y Cádiz tiene que buscar alternativas desde presupuestos distintos. Manuel Bustos, deja así una puerta abierta para aquellos que queramos profundizar en la situación de la ciudad y de sus relaciones comerciales en esos años críticos.

Guadalupe Carrasco González 


\title{
MEMORIAS DE UN MERCADER A INDIAS. IMÁGENES DE ESPAÑA Y AMÉRICA EN EL SIGLO XVIII
}

\author{
IGLESIAS RODRIGUEZ, JUAN JOSÉ \\ Puerto de Santa María, Biblioteca de Temas \\ Portuenses, 2004, 229 PÁGs.
}

Nadie niega hoy día la utilidad que para el historiador presentan las autobiografías y los libros de memorias (de todos es conocida la reciente síntesis dedicada por James Amelang al respecto), no tanto por la veracidad en sí de sus contenidos, sino por la percepción que de sí mismo y de la realidad cotidiana nos transmite el autor. Para nuestro marco geográfico concreto, desde hace mucho contamos con las memorias de Lantery, publicadas en 1949 por Alvaro Picardo, en 1983 por Manuel Bustos, y sobre cuyo contenido reflexionaron además Pierre Ponsot y Paloma Fernández, y este elenco se ha visto enriquecido con la publicación de las memorias del hidalgo y mercader portuense José Miguel Bernal, fechadas entre 1729 y 1761, a cargo de Juan José Iglesias Rodríguez, profesor de Historia Moderna de la Universidad de Sevilla, de la que es además vicerrector, y profundo conocedor de los temas portuenses, a los que en su tiempo dedicara su tesis doctoral.

El manuscrito que nos ha dejado José Miguel Bernal, bien analizado por Juan José Iglesias en una jugosa introducción, es corto en extensión, pero muy rico en contenido. Nos deja un relato de los detalles relacionados con la estancia de Felipe V y su corte en el Puerto de Santa María; aspectos relativos a las incidencias de los viajes a Ultramar, con todo su horizonte de flotas, piratas, tesoros y naufragios; acontecimientos habidos en el Nuevo Mundo, y más concretamente en la lejana Lima; reflejos de hambrunas y carestías como consecuencia de las malas cosechas de trigo en tierras andaluzas; relatos de viajes por el interior de los caminos de Andalucía; hechos prodigiosos tanto naturales como sobrenaturales; el espejo reluciente de una ciudad como el Puerto de Santa María, con un fuerte desarrollo urbanístico y de obras públicas; y, finalmente, el espectáculo y el artificio de las fiestas civiles y religiosas, todo ello relatado sin ningún propósito exhaustivo, sino, simplemente, reflejando lo que al autor le llamaba la atención en cada momento.

Que nadie piense que a partir del texto podemos encontrar un espejo fiel de la realidad portuense de la primera mitad del siglo XVIII, antes al contrario, un reflejo deformado por las vivencias y los intereses concretos del autor, aunque no debemos perder de vista que el historiador no ha de trabajar solamente con realidades (cuya aprehensión, por otro lado, es siempre escurridiza), sino también con sueños, ilusiones, espejismos, y reflejos 
deformantes (no podemos olvidar que a cualquiera de nosotros no nos interesa la realidad tal cual, sino tal como la percibimos), por lo que textos como el publicado por Juan José Iglesias siempre constituyen aportaciones de gran interés. ¡Cuántos relatos como éste permanecerán depositados en el sueño del olvido en colecciones privadas esperando su publicación;

Arturo Morgado García 


\title{
LA MEMORIA FILMADA. AMÉRICA LATINA A TRAVÉS DE SU CINE
}

\author{
PÉREZ MURILLO, MARÍA DOLORES Y \\ FERNÁNDEZ FERNÁNDEZ, DAVID (COORDI- \\ NADORES). \\ IEPALA, MADRID, 2002, 383 PÁGS.
}

La publicación de esta obra pone al alcance del público un instrumento fundamental para una aproximación a la realidad y la historia de Latinoamérica. Se trata de una inteligente combinación entre el propósito de difundir un cine generalmente muy desconocido y la pretensión de ofrecer un análisis de la sociedad latinoamericana, desde la óptica de la historia. Para ello, se adentran los autores en el "mundo simbólico y antropológico" que reflejan las películas, así como en los acontecimientos, procesos y problemas que se describen, se narran y se denuncian en cada una de las cintas seleccionadas. El resultado es un novedoso trabajo de análisis de especial utilidad como material didáctico universitario.

Estamos ante un enfoque muy interesante en el que el cine es vehículo de información a la vez que pretexto para reflejar y analizar realidades, algunas veces tratadas con tintes poéticos y las más con un sangrante tono de denuncia y crítica social . Se ha pretendido, en palabras de sus autores, "abordar el cine como fuente para la historia", dando de paso a conocer un nutrido número de títulos de un cine tan alejado de los presupuestos comerciales de consumo masivo. Esta obra es el fruto de un minucioso trabajo de equipo que necesitó dos años de debates y puestas en común entre los miembros del Grupo de Investigación «Intrahistoria y Oralidad», dirigido por la profesora Pérez Murillo. Dicho bienio de trabajo sistemático de charlas cinematográficas abarcó de noviembre de 1998 a diciembre de 2000 y fue llevado a cabo en la Facultad de Filosofía y Letras de la Universidad de Cádiz.

El libro está organizado en seis capítulos que abordan temas generales en los que se encuadran varias películas. La marginación del mundo indígena, los niños de la calle, las migraciones internas y externas, la historia colonial, el imperialismo, las dictaduras militares y la visión cinematográfica del realismo mágico -que no es más que la propia realidad en muchos casos-, sirven de marcos temáticos generales. En todos los casos se nos ofrece una explicación de la línea argumental de cada film y se profundiza en los principales personajes. Por último, se analiza el contexto socio histórico que refleja la película, apor- 
tando con ello un primer material de trabajo y una clarificadora información para quienes deseen profundizar en el tema propuesto o para quienes, simplemente, busquen en el cine algo más que evasión.

María José Portela Miguélez 


\title{
EL NACIMIENTO DE LA ACTUAL REGIÓN DE MURCIA. TRANSFORMACIONES SOCIALES Y REFORMAS POLÍTICOADMINISTRATIVAS DURANTE EL PRIMER LIBERALISMO ESPAÑOL (1810-1837)
}

\author{
María José Vilar García \\ Universidad de Murcia, Servicio de \\ Publicaciones, 2003, 430 PÁgs.
}

\begin{abstract}
El trabajo, tesis doctoral de la autora, aborda un tema poco transitado por la historiografía reciente, pero de enorme interés para apreciar el proceso de configuración territorial de las actuales provincias, según las disposiciones adoptadas por nuestro primer liberalismo. A través del estudio concreto de la delimitación de la Comunidad Murciana, la autora estudia exhaustivamente un proceso político-administrativo que puede ser extrapolable a otros casos de ordenación territorial en el tránsito del Antiguo Régimen a la contemporaneidad, de manera que el resultado final es la construcción de un modelo de estudio digno de tener en cuenta.

Comprometido fundamentalmente con un análisis espacial, que analiza la ordenación territorial llevada a cabo por las instancias liberales, el trabajo mantiene un diálogo fructífero con otras temáticas asociadas, tales como la vida económica, social, política y cultural de la Murcia de comienzos del XIX. De otro lado, el estudio del proceso institucional murciano no olvida su vertebración con el resto de la configuración nacional, como parte de un contexto más general.

El estudio se organiza en ocho extensos capítulos. El primero está dedicado a analizar el marco geográfico, las bases demográficas y socioeconómicas y el contexto histórico. Se concede especial atención a aspectos tales como el tránsito de un modelo demográfico antiguo a otro nuevo, haciendo un balance de la revolución liberal en la región e insistiendo en el carácter limitado de las transformaciones socioeconómicas experimentadas. Tras este capítulo introductorio, el núcleo del trabajo se desarrolla ampliamente entre los capítulos segundo y quinto, siguiendo una línea argumental cronológica que analiza los antecedentes históricos de la demarcación regional desde el siglo XIII al XVIII, para, después, detenerse, especialmente, en los diferentes proyectos habidos en el tránsito hacia la Edad Contemporánea, a saber: el de Floridablanca (1785-1789), la reforma de Miguel Cayetano Soler (1799-1805), los cambios introducidos por la administración afrancesada en la región, la reordenación del territorio auspiciada por las Cortes de Cádiz, los intentos del Sexenio absolutista y el decreto del Trienio liberal de 1822, el ensayo calomardino de 1825 y la división nonnata de 1829-31, precedente, éste último, poco estudiado hasta la fecha, de la definitiva reforma de Javier de Burgos en 1833. Sobre la de-
\end{abstract}


marcación político-territorial analizada, se profundiza, en los capítulos VI y VII en la configuración judicial de la región murciana, ultimada en 1834, como un aspecto fundamental de la reforma liberal. Finalmente, en el capítulo VIII, se estudian las no menos importantes demarcaciones de carácter eclesiástico y militar.

El trabajo de $\mathrm{M}^{\mathrm{a}}$ José Vilar logra superar las dificultades que presenta la ardua investigación a la que se enfrenta y es apreciable que su doble formación como geógrafa e historiadora haya jugado a favor del resultado final, abordando una temática desde una óptica novedosa, diferente a la de los tradicionales enfoques efectuados desde el Derecho administrativo. Es de destacar el cuidado aparato cartográfico que presenta y la valoración de las importantes fuentes que maneja recogidas desde los más diversos archivos. En cuanto a las conclusiones, mérito incuestionable es haber elaborado un modelo de análisis amplio y evolutivo que supera los aspectos puntuales de otros estudios, además de generar, desde esta perspectiva amplia, una lectura menos rupturista y más comprensiva de los débitos que la reforma administrativa de Javier de Burgos tiene con sus antecedentes inmediatos.

Gloria Espigado Tocino 